\title{
Bad Reputations: Memory, Corporeality, and the Limitations of Hacking's Looping Effects
}

\author{
Suze Berkhout
}

Talk about social construction and its various suffixes ("constructionism," "constructivism," "constructionist"), continues to be a popular topic within a wide range of humanities disciplines, including philosophy, science and technology studies, sociology, and cultural studies. Leaving aside the definitions and debates about what social construction refers to, and whether the view has merit (extensive reviews of both of these topics are available elsewhere: see, for instance, Hacking, "Social Construction" as well as Haslanger, "Talking About"), I want to begin with the assertion that this discourse continues to be especially meaningful in understanding the role of medical sciences in producing classifications and mediating subjectivity. In particular, thinking about social construction within the practices of medicine exposes the routes through which identity categories are stabilized within relational interactions - both interpersonal and institutional — in health care settings. It also makes explicit the ways in which classifications, as particular instantiations of judgment, can give shape and form to lived experience.

In a 1983 essay entitled, "Making up People," Ian Hacking began what would ultimately become a productive and extremely influential account of how certain "kinds" of people emerge hand-in-hand with the categories that are meant to classify them. Classification and classes, according to Hacking, emerge mutually and simultaneously in a process that he would first describe as dynamic nominalism, and later as "looping effects" (Hacking, "Making up People" 228, and "Social Construction"). Institutional practices and policies, media depictions, scientific literature - all of these contribute to the identification of certain kinds of people. Predominantly identification is done through activities of judgment. Which is to say, through activities necessary for making discriminations: counting, measuring, surveying, and grouping, to name a few. On Hacking's account, discerning a kind is not a matter of quiet fact or carving the world along natural lines; rather, it reflects societal impositions on ways of being (Hacking, "Social Construction" 28-33). 
Although his view of social construction has varied to some degree over the decades, Hacking is consistent (and I think, correct) in identifying that both text and encounter shape the process of category-making. But this analysis relies heavily on the reflexive and cognitive aspects of classification, in order to get the looping effects story off the ground. Hacking's view, for instance, would suggest that judgments that are productive of classifications are so because of their influence on the cognition of those classified, which ultimately influences action, reinforcing the classification system itself. In what follows, I examine some of the limitations of this approach. Taking up Sally Haslanger's critique of Hacking, I argue that Hacking's view places a heavy emphasis on how group members see themselves. In so doing, his account of looping effects problematically presumes that bodies of group members are shaped largely by practices that are consciously or reflexively engaged with by the individuals so classified. To that end, I bring to bear considerations of embodiment, memory, and resistance-concepts I explore within a field study of HIV/AIDS care in Vancouver, Canada- to a critique of Hacking's looping effects. My emphasis on HIV-related health services is in part a response to Hacking's own focus: while his views on social construction have been extended to a wide range of topics, Hacking himself describes his interests as resting primarily with the ways in which social, medical, and biological sciences create new classifications and new knowledge (Hacking, "Kinds of People").

I begin with an issue I found rather peculiar while carrying out field research: namely, that particular groups of health care consumers develop "bad reputations" within health care institutions. These reputations inform, and are informed by, the social identities ascribed to (supposed) group members. In Vancouver, intravenous drug users become well known amongst health care staff for actions such as leaving hospital against medical advice, engaging in drug use while admitted to care, or displaying insolent attitudes toward staff. Amongst the women who participated in the research study, those who were judged to be "difficult" patients found their ability to navigate the health care system altered; a developing identity as an HIV-positive drug user in the health care system likewise shaped further interpersonal dynamics while in hospital. With this in mind, I argue that the notion of a reputation speaks to the significant role that others' memories have in shaping ways of being in the worldways of being that may not be endorsed by the one remembered, may in fact be resisted, and yet are ultimately embodied as pathology when these reputations identify and classify those who bear them.

Haslanger's work on social construction is topical here. On her view, to say a particular "kind" is socially constructed is to say that the bases for unity amongst members are not natural properties, but social properties and relations. Moreover, Haslanger argues that a member of a 
social kind may find themselves categorized and materially affected by this grouping without endorsing or identifying with the kind (Haslanger, "Social Construction" 301-323, and "What Good" 89-118). Extending this view, I discuss that, in health care settings, we need to appreciate how classification and the process of object construction take place even as individuals resist classification. In the case study presented here, resisted classifications are intimately bound to neoliberal idealizations of the selfas-rational agent that circulate within allopathic medicine; this is a view of the self as instrumentally rational, autonomous, and self-governing. Through trope, imagery, memories, and face-to-face interactions, certain groups are depicted as opposing this normative ideal. Bringing together philosophical critique and empirical data, I demonstrate how drug users are contrasted with so-called "normal" health care users, and how these oppositions contribute to the dynamics of looping effects, and ultimately, the relational shaping of illness.

\section{Notes on Method}

With the exception of the branch of moral psychology that refers to itself as "experimental philosophy," very little philosophical work includes empirical data generated by philosophers themselves. ${ }^{1}$ More commonly, philosophers who engage in what is termed applied or practical philosophy will employ illustrations and examples gleaned from others' primary data in order to move their arguments forward. In contrast, the arguments I offer in this paper are based on data generated during my own qualitative research. In order to appreciate the cogency of my interpretation and its relevance for a critique of Hacking's looping effects, a few words on methodology will be necessary. ${ }^{2}$

Between October 2007 and January 2009, I carried out field research within the community locations where women living with HIV/AIDS accessed health care in Vancouver, Canada. This included community clinics, a women's infectious disease clinic, an emergency department and medical ward servicing the inner city population, as well as the dedicated HIV/AIDS ward of the same hospital. I also had the opportunity to spend a substantial amount of time with a number of nurses providing home-based HIV care in the inner city - an alternate model of care that provided numerous contrast and comparison points to the

1 Described as an interdisciplinary field, experimental philosophy brings together philosophical questions and thinking in metaethics and moral psychology, with the experimental methods associated with psychology. See, for example, Knobe et al.

${ }^{2}$ For more detail concerning the particulars of my research methodology and the specific problematics raised against epidemiological approaches, see Berkhout. 
primary and specialist care sites I observed. The research was designed to explore aspects of women's access and adherence to HIV care that might be missing from conventional quantitative studies; I adopted a life story methodology to do so. Seven women living with HIV, each with differing experiences in the sex trade, drug-dealing economy, foster care and corrections systems, took part in a series of open-ended interviews. Because not all aspects of inner and social life are easily articulated, participant observation also provided a crucially important contribution to the project. The women who participated in the project generously allowed me to accompany them through various aspects of the health care system, where I documented daily routines, non-verbal action, and interactions between individuals in the various field settings.

Each of the seven women identified as having Aboriginal ancestry, although they varied greatly in the extent to which they described a connection to this. Some women had lived on reserve in various parts of Canada, though many lived in primarily urban settings; some were raised in white foster families, with limited affiliation to their Aboriginal heritage. Although not exclusively negative, the connections that women identified with their immediate families were variable and sometimes tenuous. At the project's start, the participants all resided within Vancouver's inner city, and were often unstably housed. Precarious during any given month, their homes over the course of the project included shelters, tents, alleyways, single-room occupancy hotel rooms ("rooming houses"), as well as more coveted supported/social housing.

The qualitative methods I employed are indebted to my understanding of ethnographic methodology; this project was not, however, an ethnographic study. I say this in order to recognize that I did not enter into the field with the history and problematics of ethnography, as practiced by anthropologists (or sociologists, for that matter). ${ }^{3}$ I did, however, follow a reflexive, interpretive style of analysis that was informed by post-positivist epistemologies. Field observations were recorded both as jotted notes and as digital voice recordings, and transcribed following each field encounter. Interviews began my asking participants to "tell me about your life"; later, specific questions were developed from field observations and previous interviews, rather than being established a priori. I transcribed interviews myself, along with notes that detailed features of the interview itself (e.g., the setting, participants, rapport, disruptions). These aided in a reflexive interpretation of both observation and interviews. Reflexivity in particular adds

\footnotetext{
${ }^{3}$ As a philosopher, I also recognize that is not the usual way that philosophical research is conducted, and that I am not providing a philosophical accounting of the issues considered "standard" within the analytic tradition.
} 
transparency to the whole of the research process, identifying where elements of my own subjectivity as a researcher is located in the work. The reflexive component also serves to quash an attachment to "objective" reality and to underscore (rather than camouflage) the manner in which research practices shape the experiences that are represented in the final text.

Importantly, knowledge production based on interpretive analysis of qualitative data is an iterative process, not a recipe. Trying to provide a rough and ready description of how many interviews were done and what coding method was used, under which circumstances, does not do justice to the understanding knowledge production embedded in this approach. That said, the process of interpreting life stories and experiences relies on the abilities of participants to verbalize, articulate, and (critically) remember. But the act of remembering can be fraught, just as life stories themselves, when produced in a format acceptable to academic writing, can be "muffled and distorted" (Titon 277). The aspects of the stories that inform my theorizing were not excavated-they were constructed and reconfigured in the social setting of the interview and through the ongoing relationships I had with the participants. As events are reconfigured through memory, it is possible to see how they are lived in a particular time-space relationship and how they are connected to the body and its pathologies. The coding and reconfiguring were processes that I was very much a part of, as were the individuals telling their stories. At various points in the analysis and writing, I would bring presentations, ideas, and transcripts to different participants in an effort to have them collaborate on this analytic process. The end result of this work forms the empirical basis of the philosophical analysis given below.

\section{Hacking's Looping Effects: Overview and Critique}

As discussed at the outset, Ian Hacking's extremely influential account of social construction presents a view of kinds of people as products of certain institutions, languages, and practices; as "kinds" they are objects of scientific inquiry (Hacking, "Kinds of People" 292). These set conditions that various experiences of self might take. Hacking frequently uses contemporary social phenomena to illustrate his thinking and capture how looping effects happen in everyday life. In one of the more concrete explications of his thesis, for instance, Hacking gives the example of "women refugees" in order to demonstrate how a set of social conditions and practices shapes identity. An idea of women refugees as a kind of person is constructed through a series of intellectual activities: through statistical analyses and international policies, through the interpretation of social events in home countries, through legislation, lawyers, activists in other nations, as well as through historical 
understandings of asylum seekers (Hacking, "Social Construction" 10). Individuals come to recognize themselves as members of a class and subsequently go on to further shape the content of this classification. Being a member of this particular kind also means that one is able to mobilize politically around that identity; such actions shape the possible life experiences of individuals so grouped, and alter the lens through which they understand such experiences in a mutually reinforcing process.

For Hacking, women refugees come into being as a kind when these factors shape the way in which they conceive of themselves, which simultaneously causes the boundaries of classification to be re-drawn. Membership in the group entails identification of oneself with the specific group or label. Hacking articulates this same process in other instances of kind-making. In his analysis of child abuse, for example, he argues that looping effects are fundamentally linked to the notion of self-knowledge. In later work, he also emphases how classification determines "conceptual schemes," or thinkable ways of being; these reinforce the cohesion of the group in question (Hacking, "Between Foucault and Goffman" 284).

As Sally Haslanger has argued, Hacking's view of object construction is overly narrow on a number of counts, especially inasmuch as he envisions this to be a process working primarily with and on ideas (Haslanger, "Social Construction" 314). My particular interest rests with her claim that Hacking fails to address the effects of classification that can shape individuals as "kinds," but that are not internalized in the manner that Hacking tends to focus on. Writes Haslanger:

... social matrices have an important impact on groups of individuals without the group being an explicit or articulated category and without the members of the group internalizing the narrative and the norms associated with it. In other words, we need a way of thinking about "object construction" or better, the formation of social kinds, that acknowledges the causal impact of classification, but also gives due weight to the unintended and unconceptualized impact of practices. (315)

In response to Hacking's account, Haslanger argues that when schemas set expectations for behaviour and action, particular ways of being are attached to individuals who are taken to be members of the group, irrespective of their own identification with the grouping. Such schemas then mobilize other forms of interaction, whether or not any given member has a sense of cohesion or identification with the kind (see Haslanger, "What Good"). One can be identified as, rather identifying 
with, and the effects of classification may be nonetheless be engendered, without any sort of reflexive endorsement. ${ }^{4}$

I think Haslanger's view can be extended further. While a charitable view might suggest that Hacking's account leaves open the possibility of non-reflexive aspects of classification, he certainly fails to address the ways in which resisting classifications nonetheless inscribes identity. Consider that Hacking does offer childhood autism as an example of "making up people." Even in instances where autistic children themselves interact to a limited degree with their classification as autistic, those around them-their families, case workers, nurses, etc.- are influenced by the classification and its attendant concepts, shifting the borders of what "autism" entails (Hacking, "Looping Effects" and "Between Foucault and Goffman"). This is perhaps the closest that Hacking comes to articulating how classification may not depend on one's own internalization of the category.

I say "perhaps" because, although he explicitly considers whether, in a strict sense, autism is an inaccessible classification (i.e., a classification inaccessible to the persons classified), Haslanger's concerns may still be germane. Hacking states that despite challenges in language and socializing, many children classified as autistic learn how autistic children behave through interactions with autistic peers and through looping effects at an institutional level (Hacking, "Between Foucault and Goffman"), a depiction that resonates with his earlier, self-knowledge focused version of social construction. But when we unpack his use of the term "inaccessible classification" claim further, we're left with a different problem altogether: to use Hacking's example as a rebuttal to Haslanger's critique would mean accepting a framing of autism that is itself problematic, especially from a critical disability studies lens. Autism as an "inaccessible" classification plays off of the notion that those classified as autistic are somehow not also thinking, feeling people, who have ideas about themselves and the world - an unsophisticated and troubling set of presumptions that have been roundly critiqued both from inside and outside of autistic communities. That said, setting aside the problematic aspects of this example, and granting that there may be some interpretive space within the concept of "inaccessible classification" to address Haslanger's worry, Hacking's larger body of work on looping effects does

\footnotetext{
${ }^{4}$ I note that Haslanger asks this question not because she is particularly concerned about embodiment in Hacking's work, but because she is interested in semantic externalism, and the revolutionary (and debunking) power of critiquing the problematic implications or presuppositions regarding a particular grouping or class. Nevertheless, her point is apt for my purposes as well.
} 
not address the ways in which one might resist categorization and still be materially affected by it.

Hacking does not seem to consider, for instance, how the adoption of a social identity might be strategic, rather than an outright endorsement, and yet produce the sorts of effects he's interested in. In my own research, women involved in the project would sometimes refer to themselves as a "fiend" or "junkie," self-designations that were used in a strategic rather than classificatory sense. Invoking the image of a drug user was one way to rationalize and minimize actions that could be construed by medical authorities as non-compliant or manipulative. "I'm just a junkie," stated sarcastically, might be given as a form of protest against mistreatment, albeit one that is "safer" than an outright claim would be. Employing terms that enable sarcasm, but that allow others to minimize the protest, are a way to negotiate the "regimes of silence" that are part of women's lives in Vancouver's inner city community. The strategic use of the category does not disrupt or reshape the contours of grouping - as a form of resistance it is "safe" just because it maintains the status quo.

Likewise, Hacking under-theorizes the impact of social structures and cultural practices on the body, and the relationship between embodiment and the non-reflexive effects of looping effects on social kinds. This is not to say that he is entirely remiss on the topic; his work may indeed resonate with a number of theoretical tools useful to understanding embodiment. In a rich discussion of looping effects and what it means to make up people, Hacking frames his own work in relation to that of Erving Goffman, highlighting the productive effects of social stigma, itself indebted to a history of bodily markings and signs. Hacking also offers that his work has some intellectual affinity with that of Bourdieu, whose scholarly contributions include thinking through the manifestations of classification in gestures, body language, and habitus. Nonetheless, Hacking offers these as compatible with his view, rather than incorporating such insights into his account itself. With these limitations in mind, I turn to the notion of "bad reputations," and the way that the social and cultural domains of memory inform social identity, in order to motivate my claim that looping effects may be embodied, even as classification and categories are resisted.

\footnotetext{
${ }^{5}$ Robertson and Culhane (9) employ this term to describe the complicated realities within which women live in Downtown Eastside Vancouver.
} 


\section{Bad Reputations}

During the fifteen months that I carried out field research, I was surprised by the number of instances that health care providers would reference the reputation that a given participant had within the health care system. This seemed to be part of a larger process within the medical settings where I was located. For instance, I would hear numerous broad generalizations of street-involved individuals as the "frequent fliers" of the health care system, denoting a kind of casual familiarity between staff and repetitive users of the system (minus any special benefits or points cards). In addition, particular individuals from the inner city community would become well known amongst health care providers, made familiar by their so-called bad behavior. Particularly well-remembered were those "frequent fliers" whose actions included leaving the hospital against medical advice, using illicit substances in hospital, or demonstrating "attitude" to staff. Behaviors were copiously documented in nursing notes, medical charts, and discussed on morning rounds. Staff would reminisce, sometimes fondly and sometimes not, about behavior they considered particularly outlandish-patients who dealt crack out of their hospital beds, patients who left hospital abruptly with surgical equipment still attached, and one patient who occasionally hired sex workers to see him while in hospital.

A number of the women I worked with throughout the project were considered to have such reputations. Specific recountings of their previous behavior were made while they were receiving care. This was accompanied by the notion-both tacitly and explicitly-that their past was shaping what health services would be available to them in the future. Making explicit that certain actions would have service-related consequences was likely part of an effort to avoid wasteful health expenditures (the same patients would also be told how much their medications were costing the system). It certainly was an attempt to instill a kind of self-governing consciousness amongst the "problem" patients. ${ }^{6}$

One such woman was admitted to hospital in 2008 for a diagnosis of HIV-related cancer. When first admitted, there had been a push by hospital staff to keep her in hospital for the duration of her chemotherapy, as she had been, until then, living in an alley doorway. To discharge her to a shelter with the expectation that she would present herself to the cancer

\footnotetext{
${ }^{6}$ I note that this practice did not likely extended to the wide range of individuals who were non-adherent with care while in hospital. As one infectious disease specialist described, the metabolic syndrome patients who aren't able to change their lifestyles and the eating disorder patients who continue to purge or pull out their feeding tubes are typically treated with more compassion than the individuals whose addictions challenges continue to bring them to hospital, despite the rhetoric that addiction is a "brain" disease.
} 
agency across town to continue chemotherapy, was deemed unrealistic by the medical team. But after a number of self-discharges from hospital, and subsequent re-admissions with new infections and complications, she was a less welcome face on the ward, and was described to me as having an "edge" that hadn't been there before.

Fieldnotes, October 22, 2008

Missy tells me that she found out that she's not going to get any more chemotherapy. "It's my own fault," she says. I ask her if she feels that we (myself, hospital staff) could have done more for her. She says no, "it was me. I wasn't where I was supposed to be." I ask her if the answer about chemo was never, or if it was, not right now, based on your life circumstances. She says, "it was never, never, never again, you're going to die. At least, that's how I look at it." I ask her if she wants me to talk to the staff about it, she says no, she should just accept that there will be no more chemo. When I follow up on the ward, a staff member says that the cancer agency will give her an appointment later in the month and that if she makes it to that one, they'll look at restarting chemotherapy. She tells me that Missy has gotten herself a reputation for taking off and the docs don't want to deal with her.

Every time she left hospital and returned with another opportunistic infection, or came back high after leaving for a cigarette, Missy cemented her developing reputation: that she was an intravenous drug user (referred to in the scientific literature by the acronym "IDU") who was non-adherent to her antiretrovirals and chemotherapy regimen. Bodily markings typically associated with the IDU category would be noted and related to the events on the hospital ward, despite the fact that alternate explanations could be given for their presence.

For instance, early in 2008 she frequently had cellulitis-a bacterial skin infection commonly associated with injection drug use-in her lower legs. In her case, these episodes related to skin breakdown from swelling, which was secondary to a poorly functioning lymphatic system in the context of her cancer diagnosis and treatment. When she appeared in the emergency department with cellulitis, the presumption was that the infection related to non-sterile injection practices, despite her articulation that she did not inject drugs (she smoked crack and heroin). As each encounter became formalized in her medical records, her classification as an "IDU" was solidified, despite the fact that she had never actually used a needle. At some point in the process, I saw that IDU was indeed marked in her chart. Any drug use at all, along with the diagnosis of HIV infection and residence in the inner city, was enough to be classified according to the well-established risk group, despite the lack of appropriate bodily practices. With her reputation for leaving hospital against medical advice, 
and the IDU label in place, physicians were less willing to advocate for her to remain in hospital to complete the therapeutic regimen.

I found the notion of Missy having developed a reputation noteworthy. To my mind, she had been classified as a social kind (an "IDU") $)^{7}$ according to a set of proxy behaviors and bodily markings, despite the fact that she did not identify as a bona fide member of the group. It also meant that the nurses and physicians had memories of her. Their encounters with her and their interpretations of her behavior at any given point in time were referenced to her past, setting up expectations for her future actions. These expectations shaped the reception she would get in the emergency department and on the hospital ward when she was readmitted, and informed the standards of behavior that she was expected to meet, if the health care team were to move forward. Importantly, these standards shifted as time went on-becoming more difficult for her to achieve, and acting as confirmation of her grouping as a particular social kind. All of this contributed to on-going ill health and the tense dynamic that played out in the decision around continuing chemotherapy.

Two aspects of this are of interest. First, the personal experiences of health care staff shifted from amorphous memory to seemingly more factual "history" as all of these comings and goings were documented in the medical chart. ${ }^{8}$ It struck me as not unlike an act of memorialization: a social process in which remembering is concretized as the property of material artifacts and social practices (rounding, charting, documenting), and through which a veneer of objectivity develops. As artifacts of representation, these material objects give "reality" to the past (Withers 325-344). Moreover, certain representations are suggested and codified as legitimate as they become (literally and symbolically) inscribed; certain

\footnotetext{
${ }^{7}$ I apply the term social kind to the "IDU" grouping here (rather than simply "drug user") because IDU is a specific risk group employed in epidemiological research and associated with HIV infection. Importantly, the ontology of epidemiological methods treats classifications such as IDU as metaphysically objective-commonalities between members of the group IDU has to do with the actions of group members (injections of illicit substances) and not their relationship to how the grouping takes place in practice. The IDU grouping is more than simply non-arbitrary. Current views on dopamine sensitivity as well as the impact of early life experiences on injection drug use within addictions research, in addition to medical views of drug use as a brain problem, effectively naturalize the IDU category and represent drug users a kind of person. As such, it has particular significance as a socially recognizable identity.

${ }^{8}$ The relationship between memory and history is complicated, and I do not presume to give an overview of how the two terms are intertwined, nor where they come apart. That said, they are frequently treated as representing different interests and epistemologies. To paraphrase Klein (130), history has frequently been taken as objective in the hardest, coldest sense of the word, and memory treated as its antonym-subjective, warm, and inviting. On this topic, see also Withers 326.
} 
values portrayed and endorsed, while other perspectives are disallowed or subverted (Levine 117-118). But whereas public memorialization frequently invites a variety of perspectives and meanings attached to a given memorial site (Capozzola 91-109), medical charts offer a much more narrow view of reality. There are sections for various health professionals to give their discipline-specific observations. Documentation is written in a highly stylized way, typically the "SOAP" note that categorizes clinical data as either Subjective or Objective, and then goes on to detail an Assessment and Plan. The perspectives of health care staff are "objective" in contrast to the "subjective" information that is given by patients, rhetorically resonating with the idea that only some views acquire the status of fact (Donnelly and Brauner 481-484). Charts are also legal documents, and writing is done with an eye to liability and completeness from the health care providers' perspective. Finally, it's worth noting that proper documentation a learned skill, suggesting that particular interests and perspectives are stylized within the practice. As bad reputations developed on the hospital wards, they were solidified as historical records and sanctioned by the practices associated with charting.

Second, as the notion of a "reputation" suggests, others' memories are also significant and may attribute identity over time, whether that identity is apt or desired. Naomi Scheman describes this evocatively:

Insufficiently noted by philosophical theorists of personal identity is the role of the memory of others in constituting selfhood. It is not just that we are the persons we remember ourselves being: We are equally, for better or worse, the persons others remember us being. The others around us may be loving or arrogant, thoughtful or careless, with their memories of us; and we can be grateful or resentful or both for being held in their memories, for being continuous with the persons they remember us being. (Scheman 125-126)

As Scheman highlights, the relationship between memory and identity for philosophers has been typically referred to the continuity of one's own memories through time. But in describing how others' memories may not be shared with the one being remembered, Scheman argues that it is a matter of privileged subjectivity when one's own memories and subsequent sense of self find convergence with others. Some lives, in contrast to the seamlessly integrated narrative, are distorted or fractured. When particular memories become reified and memorialized, for instance as they are documented within medical charts, those memories shape identity and lived experience.

The version of events recorded in Missy's medical chart and memorialized in conversations did not belong to Missy herself; these were also not "shared" memories, at least in the sense that she adamantly 
resisted them. But as her reputation became increasingly calcified by subsequent identifications as an injection drug user who did not comply with medical care, health care providers were less willing to give Missy the benefit of the doubt with respect to her intentions. This translated, in some instances, into having fewer supports offered. The official record of her removing herself against medical advice overwhelmingly invoked an identity that was deemed to be "chaotic," a term that embeds within it imperatives and cultural taboos against drug use and euphoria, as well as transgressed norms of rational agency. Rarely were contributing factors considered in the historical record: these included challenging interpersonal dynamics that she faced with certain hospital staff, the difficulties she faced as an economically disadvantaged Aboriginal woman in a very Caucasian institution, or the legitimate emotional challenges she faced in coping with multiple life-threatening diagnoses.

The externalization and concretization of embodied experience plays an important role here: the presumption of a transgressive social identity and its concomitant reputation contributed to conditions within the health care setting that made complying with treatments challenging; viral replication increased when treatments were not followed closely, and subsequent opportunistic infections and pathological processes continued. The downstream effects were then read off of particular tissues and bodily fluids that were biopsied and sampled in an effort to provide further medical diagnoses and care. Schemas ${ }^{9}$ and cultural images of drug usersas dependent, manipulative, dangerous, and irrational-filled in missing details and swept away uncertainties that might have existed in the shift between memory and history. By way of setting expectations for behavior and action, particular ways of being are attached to individuals who are taken to be members of the group represented by the schema, which then mobilize other forms of interaction (Haslanger, "What Good" 80-118). IDU schemas influenced the possible trajectories that clinical encounters might take, without requiring that individuals reflexively endorse the social kind. Even when women such as Missy would attempt to resist others' memories of them, for example by offering a reinterpretation of the events that had led to another instance of "bad" behavior, these schemas were invoked. When certain perspectives and memories were preferentially endorsed over others, the effects of classification were ultimately embodied as familiar patterns of cellulitis and opportunistic infections that typically afflict drug users, as women withdrew from health care services as a form of protest against classification.

\footnotetext{
${ }^{9}$ If we think of schemas as mental constructs that function much like a script would, we can see how behaviours, actions, and events can be interpreted in light of them, even where explanations are ambiguous or incomplete. Individual memories play into schemas (and vice versa), providing emotional salience and strength of association.
} 
As patterns of pathology are attributed to the individual's social identity rather than to the conditions of care, the strength of the grouping and its association with particular health outcomes is bolstered. Looping effects are manifested as phenotype; in turn, the cogency of health care providers' original judgments is reinforced. This sort of case presents some difficulty for Hacking's position: there is little room to appreciate the way in which memory becomes embodied as history, and how this process need not be endorsed by the object of classification. It would seem, in fact, that the role of others' memories in the processes of classification are more poignant in just those cases where the friction and resistance to what has been remembered exists between individuals with differential authority and standing within the institutional structures at hand.

\section{Ideology and Object Construction}

Others' memories, depending on who those memories belong to, have a way of making up networks of privilege and power, and significantly shape the corporeal self. By having a reputation as someone whose drug use was rendering her life increasingly "chaotic," Missy was implicitly (and at times, explicitly) held against the normative ideals of rational agency. Such idealizations have a foundational role in establishing looping effects, particularly in those situations where reflexive endorsement is not at play.

Consider, for example, how caricatures of drug users are contrasted against idealized individuals who manifest elements of the norms of individualism and rationality, as well as moral character and responsibility. Culturally entrenched figurations of socially excluded groups ("the junkie," "the criminal," and "the mad"), have a way of becoming fundamental organizing principles (Meyers 54) that extend well beyond the individual imagination to structures and institutions that shape how people are able to interact with one another and move about in the world. Held up against a normative ideal of the rational agent, this imagery can authorize discriminations and structure moral choices and epistemic projects (53). Idealizations of the self-and their binary oppositions - are part of a moral and emotional matrix of the healthcare system, ultimately shaping corporeal experience.

Field Notes: January 16, 2009

Tina and I are sitting on the metal steps of the fire escape of her building, with our backs to the goings-on of the alley. It's cold out, but it isn't raining. There was already a piece of cardboard on the step where we decided to plunk down, so we sit there, huddled from the wind. We've been talking about how she came to be living 
in the Downtown Eastside, after running away from her adoptive family as a young teenager and being set up to hustle by a boyfriend. She pauses from the story to take a toke from the piece of rock she will eventually smoke over the course of the afternoon. The smoke has a bitter, chemical smell to it as it wafts past me.

When I ask Tina about what happened the last time she was in hospital she says that people there treat you like dirt, "because you're a junkie." She says that they don't believe you, that you're in pain, or that you're in withdrawal. She says that even though she wouldn't wish the kind of pain she has on her worst enemy, she does wish they [the hospital staff] could feel what it was like, "even just for thirty minutes." She says they wouldn't be able to handle it, but then they'd know what it was like. I ask her what she would say to people at the hospital, to tell them about it. She corrects me, saying that it's not the kind of pain you can describe, that you have to experience it. She says that she's never been so dope sick as the last time she was in hospital, when they didn't give her anything for her opiate dependency-"no morphine, no methadone, no nothing." Her home care nurses made it up to the ward on the weekend and stayed there with her until the methadone dosing was straightened out. She says that they're the only reason she was able to stick it out, after two days straight of vomiting, sweats, shakes and diarrhea. She was ready to take off, because of the withdrawal and the pain. But, she tells me, it's a good thing she didn't, she wound up being in there for three weeks.

For Tina, being classified as a drug user translated into troubled interpersonal interactions regarding pain medication and methadone maintenance therapy within the hospital setting. It's important to consider that, unlike Missy, Tina did in fact use injection drugs; in some sense, then, the classification is apt. But she also resisted being identified and treated as a drug user, in particular protesting the classification when it meant that her experiential assertions (e.g., of pain) were not recognized as believable. Her experience highlights the way in which attempts at resisting classification may shape what actions are available, and reinforce outcomes that are associated with particular kinds of people. In some sense of the word, Tina was planning to leave the hospital to "get drugs," and would have done so if her home care nurses had not been able to intercede as credible witnesses. But the drug she needed was a prescribed medication - methadone - which she had not been receiving in adequate dosages while in hospital. Had she left against medical advice on that first weekend, the negative impact on her health would have, in all likelihood, been quite significant. It's also very likely that the event would have been documented as a form of non-compliance attributed to injection drug use (rather than methadone maintenance). This is precisely the sort of event 
that would continue to reinforce the relationship between drug use and non-compliance that is envisioned within the HIV/AIDS literature, despite its departure from the usual causal story.

"Kinds" of people, writes Hacking, are thought of as definite classes defined by definite properties (Hacking, "Kinds of People" 293). Sociologists, epidemiologists, and physicians amongst others, try to understand and intervene on the class-property relationships to make improvements health outcomes. What I have been suggesting, however, is that the seemingly obvious class-property-outcome relationship, as it applies to the IDU category, is not timeless, straightforward, or natural. Some individuals manage to get classified as IDU even if they've never used injection drugs and protest their classification; some individuals can indeed be classified as IDU based on particular properties, but these factors do not strictly relate to outcomes such as poor health in the causal way envisioned by researchers. The persistence of medical charts, along with the clinical data and observations within them, also means that classifications have a way of persisting, despite the fact that they may no longer be apt. Even if an individual no longer injects drugs, they are marked as having done so - and the attendant features of the schema are applied. Again, this sets up the dynamics of looping effects, without necessitating reflexive engagement with the category.

But how much of this relates to the opposition between categories such as IDU and idealizations of the self-as-rational agent within medicine, as I claimed at the outset? One might be tempted to suggest that perhaps the reputations and resultant effects I documented during the project were simply poor behavior on the part of health care staff; behavior informed by privilege and authority, but not linked in to any deeper ideological commitments. Consider again Tina's experience. With both outright declarations that her pain was not taken seriously, as well as with less explicitly confrontational encounters, Tina described how she, as a drug user, feels as though she is seen as an individual who is not trustworthy and who lacks dignity. These are all characteristics that oppose normative ideals of rational agency.

These characterizations did not simply apply to Tina. Departures against medical advice, missed appointments, and unfilled prescriptions for a number of study participants were discussed and documented as patterns of non-compliance; such events were also understood by health professionals in relation to rationality. On the hospital ward and in clinics, drug-using patients who acted against medical advice were described as "impulsive" and "childish," particularly when they did not follow medical advice. Infantilizing language and imagery commonly applied to the IDU category serves to diminish credibility and rational authority, given that children are not thought to be able to achieve the standards of autonomous rational agency. As feminists have persuasively argued, historical 
representations of femininity have been linked to child-like behaviorfrivolous, silly, head-in-clouds-stereotypes meant to depict women as oppositional to the so-called man of reason (Code 195). Using the language of childishness in clinical settings similarly diminishes the ability of those depicted by such imagery to make claims and demands against others who are held as paradigms of reason.

Perhaps more telling are the underlying views of rational agency that function within models of health behavior and compliance (often referred to in the literature as "adherence," a term meant to be more inclusive of patients' own interests). Research and analysis of adherence has been strongly influenced by health behavior models, developed outside of the domain of antiretroviral therapy, such as the Health Belief Model, Social-Cognitive Theory, Theory of Reasoned Action, Theory of Planned Behavior, and Protective Motivation Theory (Simoni et al. 515, Munro et al. 104). These accounts emphasize the necessity and significance of adequate and reliable information in order for agents to carry out health-related actions. Such models also presume that agents have a relatively stable set of priorities and preferences, which may be modified by additional propositional knowledge. Moreover, there is a presumption within these views that deliberative processes will be undertaken so as to attain the greatest possible preference set amongst the stable, ordered preferences and priorities. ${ }^{10}$

A number of features of health behavior theories are shared with neoliberal conceptions of the self-as-rational-agent and rational autonomous agency, which are worth dissecting. In both, agents have certain desires (e.g. to be asymptomatic) and beliefs about how to achieve them. They go about discharging those through actions such as following through on medical advice, taking pills, etc. Health behaviors are understood to be the result of means-end deliberation, which motivates the action to be carried out. This view of health behavior is incorporated into research models, and is likewise employed in clinical settings. For instance, in a hospital rounds presentation discussing how it is that some individuals living with HIV/AIDS in Vancouver, Canada manage to be treatment successes, Victoria Alfonso and Junine Toy describe that, "patients who take the time to reflect, consider their situation, and make conscious choices are more likely to maintain adherence" (Alfonso and Toy). Being "ready, willing and able" to commit to medications requires behavior change: one must move from being pre-contemplative about their behavior to being able to think about making changes, resolve any ambivalence, prepare to undertake action, and then follow through with

\footnotetext{
${ }^{10}$ For a description of such models of action, see Simon 99.
} 
initiating action. By referring to those who are adherent as "committed" to treatment, responsibility is invoked.

Just as in the need for reflective deliberation, sustaining behavior change requires self-monitoring of new behavior. Even analyses of adherence that attempt to include factors such as perceived social support often share these features of behavior change theory (Simoni et al. 515). Thus, following medical advice (e.g., pill-taking, remaining in hospital) seems to implicitly follow a model of rational autonomous action, whereby a patient reasons and follows through on consciously endorsed decisions as an expression of the integration of their core beliefs and desires, making them thereby responsible for those decisions. ${ }^{11}$ Schemas of drug users, evidenced by the pejorative language used to describe drug users' inability to follow through on medical advice, operates within this larger neoliberal framework. This imagery intersects with that of HIV/AIDS as itself a manifestation of irrational action, desire, and transgression (Waldby 6). Thus a wider set of judgments relating to idealizations of rational agency form the foundation from which classifications are mobilized. This urges a reconsideration of looping effects - not as thinkable ways of being, as Hacking would articulate, but as a cascade of social effects that are premised on, and enacted through, differential bodily possibilities.

\section{Concluding Thoughts}

History is not merely a narrative or the sum of competing narratives. It is also what is inscribed within our bodies and makes us think and act as we do. (Fassin xix).

If various groups and individuals can find themselves on the wrong side of history, perhaps we also need to consider the ways in which ideologies surrounding rational agency can mean that some find themselves on the wrong side of memory. In this paper, I've attempted to

\footnotetext{
${ }^{11}$ In a recent edition of Bioethics, Gillett examines this usual interpretation of autonomy as a form of self-rule that follows a means-end reasoning process, suggesting that the emphasis on internal reasons (beliefs, desires, states of mind) seem to produce the unsettling idea that rational conscious choice is an illusion, given that brain events are not under rational control (Gillett 331). The notion that inner processes (e.g. nerve pathway signaling cascades) are the "real" causes of human action is problematically reductionist - as Gillett argues, human action is more often a result of a subject engaging in a "dynamic flow of discursive activity reflecting and influencing his/her thinking in a holistic loop" (333). In Gillett's words, decisions are not circumscribed events in neurotime (ibid). While internal brain events are not irrelevant, they are not definitive of rational agency.
} 
explore some of the ways in which the construction of social kinds is tied in with identity formation, albeit not simply in the way that Hacking articulates. Social identities are informed by reputations, others' memories, and their relationship to wider cultural schemas and images. These can generate looping effects even when the social identity of the grouping is not straightforwardly internalized. The relationships between looping effects, memory, and normative views of the self are particularly pertinent for those who find themselves faced with schemas and narratives that are contested and resisted. ${ }^{12}$ Ultimately, norms of universality, rationality, objectivity, and epistemic authority are lived as bodily experience, constructing social kinds in ways that do not depend on reflexive endorsement or self-conscious reaction to classification. By exploring these relationships, this paper offers an additional way of thinking through the social-historical in determining experiences and bodily practices that shape identity. Moreover, as my empirical work has tried to demonstrate, this thinking has strong implications for the role played by medicine in the processes of self-making. ${ }^{13}$

\footnotetext{
${ }^{12}$ I have focused specifically on the intersection of gender stereotypes and schemas of drug users, though it is notable that further pejorative tropes-racialized and classbased-are also likely to function within the field setting I have been discussing. My lack of emphasis in this paper is not meant to undermine the importance of intersecting identity categories, but rather reflects the concerns that participants themselves brought forward with respect to those classifications they resisted and refused while in the health care system.

${ }^{13}$ I am grateful to the women who participated in the project, for their time and efforts. Thanks also to Scott Anderson and Sally Haslanger for their helpful comments on earlier drafts. Versions of this paper were presented at the 2012 Canadian Society for Women in Philosophy conference, as well as at Carleton University. Special thanks to Alexis Shotwell, Abigail Kidd, Melinda Spry, and Kayla Turpin for their generous feedback. Funding was provided by the Canadian Institutes of Health Research, The Michael Smith Foundation for Health Research, and from Pfizer Canada. The project was approved by the UBC Research Ethics Board, Vancouver Coastal Health Research Institute, Providence Health, Vancouver Native Health Society, and BC Women's and Children's Hospital.
} 


\section{Works Cited}

Alfonso, Victoria, and Junine Toy. Uniting Forces: The Role of Pharmacy and Psychology in Facilitating Adherence. Vancouver: AIDS Care Rounds, St. Paul's Hospital, 2007.

CAPOZZOLA, Christopher. "A Very American Epidemic: Memory Politics and Identity Politics in the AIDS Memorial Quilt, 1985-1993." Radical History Review 82 (2002): 91-109.

CODE, Lorraine. What can she know? Feminist Theory and the Construction of Knoweldge. Ithaca, NY: Cornell University Press, 1991.

DONNELLY, William and Daniel BRAUNER. "Why the SOAP is bad for the Medical Record." Archives of Internal Medicine 152, no. 3 (1992): 481484.

FASSIN, Didier. When Bodies Remember: Experiences and Politics of AIDS in South Africa. Berkeley: University of California Press, 2007.

Gillet, Grant. "Intention, Autonomy, and Brain Events." Bioethics 23, no. 6 (2009): 330.

HACKING, Ian. "Making Up People." Reconstructing Individualism: Autonomy, Individuality, and the Self in Western Thought, Eds. T. Heller, M. Sosna, and D. Wellbery. Palo Alto: Stanford University Press, 1986. 222-236.

-. "The Looping Effects of Human Kinds." Causal Cognition: An Interdisciplinary Approach. Eds. D. Sperber, D. Premack, and A. Premack. Oxford: Oxford University Press, 1995. 351-383.

-. The Social Construction of What? Cambridge: Harvard University Press, 1999.

-. "Between Michel Foucault and Erving Goffman: Between Discourse in the Abstract and Face-to-Face Interaction." Economy and Society 33, no. 3 (2004): 277-302.

-."Kinds of People: Moving Targets." Proceedings of the British Academy 151 (2007): 285-318.

HASLANGER, Sally. "Social Construction: The Debunking Project." Socializing Metaphysics: The Nature of Social Reality. Ed. F. F. Schmitt. Oxford: Rowman \& Littlefield Publishers, (2003). 301-323.

-."What are we Talking About? The Semantics and Politics of Social Kinds." Hypatia 20, no. 4 (2005): 10-26.

-."What Good Are Our Intuitions: Philosophical Analysis and Social Kinds," Proceedings of the Aristotelian Society Supplementary Volume 80, no. 1 (2006): 89-118. 
KLEIN, Kerwin Lee. "On the Emergence of Memory in Historical Discourse." Representations 69 (2000): 127-150.

KnoBe, Joshua, et al. "Experimental Philosophy.” Annual Review of Psychology 63 (2012): 81-99.

LeVINE, Michael. "Mediated Memories: The Politics of the Past." Angelaki, Journal of the Theoretical Humanities 11, no. 2 (2006): 117-136.

Meyers, Diana. Subjection and Subjectivity: Psychoanalytic Feminism and Moral Philosophy. New York, NY: Routledge, 1994.

Munro, Salla, et al. "A Review of Health Behaviour Theories: How Useful are These for Developing Interventions to Promote Long-term Medication Adherence for TB and HIV/AIDS?” BMC Public Health 7, no. 1 (2007): 104.

Robertson, Leslie, and Dara Culhane, Eds. In Plain Sight: Reflections on Life in Downtown Eastside Vancouver. Vancouver: Talon Books, 2005.

SchEMAN, Naomi. "Queering the Center by Centering the Queer: Reflections on Transsexuals and Secular Jews." Feminists Rethink the Self. Ed. D. T. Meyers. Boulder: Westview Press, 1997. 124.

SimON, Herbert A. 1955. "A Behavioral Model of Rational Choice." The Quarterly Journal of Economics 69, no. 1 (1955): 99.

Simoni, Jane, Cynthia Pearson, and Robert Malow. "Strategies for Promoting Adherence to Antiretroviral Therapy: A Review of the Literature." Current Infectious Disease Reports 10, no. 6 2008): 515.

Titon, Jeff Todd. "The Life Story." The Journal of American Folklore 93, no. 369 (1980): 276.

WAldby, Catherine. AIDS and the Body Politic: Biomedicine and Sexual Difference. New York: Routledge, 1996.

Withers, Charles. "Place, Memory, Monument: Memorializing the Past in Contemporary Highland Scotland.” Ecumene 3, no. 3 (1996): 325-344. 